\title{
A first empirical analysis of JIS lifespan
}

\author{
- Implications for the review system of de jure standards-
}

Suguru TAMURA ${ }^{1,2,3}$

In this study, we normatively discuss the road map scenario to improve the management system of standards and then to improve the national innovation system. In AIST, there are many research projects of standards' generation, but the research about the management of established standards is rare. For this purpose, factors related to the lifespan of de jure standards are examined. We especially focus on the effect of technological categories of standards on lifespans. Under the system used by the Japanese Industrial Standards Committee, the review period for standards is five years, and it has not been changed for several decades. The system of ISO has been in the same situation for several decades as that of Japan Industrial Standards (JIS). By using the record of about 4500 JIS standards, the de jure standards of some industrial technology areas are shown to have a tendency toward longer lifespans. Depending on the obtained study results, we proposed a road map scenario to improve the national innovation system through the management of standards, which incurs less administrative costs and makes timely market creation.

Keywords : Lifespan, de jure standard, review interval, technological category

\section{Introduction}

In this study, we normatively discuss innovation to improve the management system of standards in a science and innovation policy perspective. For this purpose, we focus on the review system of the standards. Through this study, we have found that the review intervals of standards are fixed regardless of technological fields and the system has been the same for decades from the previous century. This system is the same for international standardization organization such as International Organization for Standardization (ISO) and de jure standards in Japan.

The research on standards in terms of innovation management is still in its introductory phase. ${ }^{[1]}$ This study focuses on de jure standards, as set by governmental agencies, rather than on de facto standards, which are the results of market competition. De jure standards are fundamental for innovation. For example, MPEG (Motion Picture Experts Group), the digital format for exchanging moving pictures, is standardized as a de jure standard and is widely used to exchange digital movies. ${ }^{[2]}$ A topic of research in the formation of the standards is the parallel development of standards and R\&D activities. However, in the case of R\&D of a public research institution in Germany (BAM: Federal
Institute for Materials Research and Testing), previous research pointed out that standardization does not move parallel to the R\&D results of published papers in the field of basic research.$^{[3]}$ This implies that the formation of standards does not necessarily contribute directly to innovation. In the case of the US research institute for standards, the National Institute of Standards and Technology (NIST), the evaluation of individual R\&D projects is still in the preliminary stage. ${ }^{[4]}$ This case also shows that the formation of standards (preformation) itself is only a part of the national innovation system and we need to explore how to manage standards (post-formation). In this study, we explore the management system of formed standards, with the aim to achieve an efficient national innovation system. We suggest a road map scenario, which includes both pre-standardization and poststandardization steps to improve the national innovation system through an efficient management system of standards. We base our analysis on the survey of a number of research articles related to standardization released by the National Institute of Advanced Industrial Science and Technology (AIST).

In this study, we focus on a public national research institution, AIST in Japan, as in the above-mentioned research in Germany. ${ }^{[3]}$ In AIST, there are many research projects

1. Research Institute of Economy, Trade and Industry (RIETI) 1-3-1 Kasumigaseki, Chiyoda-ku 100-8901, Japan, 2. Research Institute for Science and Engineering/Comprehensive Research Organization, Waseda University 3-4-1 Okubo, Shinjuku-ku 169-8555, Japan, 3. Policy Alternatives Research Institute, The University of Tokyo 7-3-1 Hongo, Bunkyo-ku 113-0033, Japan E-mail: tamura.edu@nifty.com

Original manuscript received May 13, 2016, Revisions received July 15, 2016, Accepted July 15, 2016 
focusing on standards' generation, but there seem to be no research on how to manage already established standards, in their innovation scenarios. There has been little research and almost no discussion about the role of standards after their formation for the transformation of laboratory technologies into market practices. More discussion is needed on this issue in terms of integration of related elements including both social and technological factors. ${ }^{[4]}$ We especially need further discussion to clarify the links among R\&D results, standards' formation (pre-standards' formation) and standards' management (post-standards' formation) in different innovation scenarios, both nationally and internationally. The OECD Frascati manual, the international guideline for innovation measurement since 1963, does not discuss how to manage already formed standards. ${ }^{[5]}$ From the economic perspective, researchers have been focusing more on why and how standards are formed, rather than how we normatively manage already formed standards. ${ }^{[6]-[9]}$

How do scholars and practitioners approach the topic of standards' management after they are formed? One fundamental aspect is the lifespan of standards. The importance of this aspect is easily inferred from the case of patents and copyrights. The legal lifespan of patents and copyrights is a key factor to determine the value of patents and copyrights, after they are formed. The legal lifespan of patents is 20 years in Japan, but in some technology areas, like biotechnology, it can be extended to protect the value of patents. The lifespan of patents is a matter of value management for innovation. We ask whether we already have sufficient knowledge about the lifespan of standards to manage existing standards. It seems clear that we do not. We have surveyed the existing knowledge and several factors related to the lifespan of de jure standards, which are examined from the standards' management prospective. Among all factors, we focus on the effect of the technological category of standards on their lifespans. Our results suggest a management system of standards leading to less administrative costs and achieving timely market creation. This management system is normatively presented in a following road map scenario for innovation.

\section{Background}

In AIST, there are many research projects reflecting a wide range of technology sectors. In addition, several research projects involve standardization. AIST is organized into 5 departments and 2 centers, which range from life science and information technologies. Its budget is about 1269 million USD for 2014. AIST is conducting research with a focus on industrialization. It has about 2200 researchers and it is one of the largest R\&D institutions in Japan. The institution is also in charge of national measurement standards in Japan, like the National Institute of Standards and Technology (NIST) in the US. It promotes international standardization as part of its open innovation strategy. ${ }^{[10]}$ In terms of policies, AIST is an affiliated agency of the Ministry of Economy, Trade and Industry (METI). METI is in charge of the management and formation of de jure standards in Japan, known as Japanese Industrial Standards (JIS), and of the country's innovation policy. Because of this twofold organizational structure, there is much research related to standardization conducted at AIST, in various technology fields. In addition, the AIST staff plays a key role in both the committees of the International Organization for Standardization (ISO) and the International Electrotechnical Commission (IEC). While 48 researchers from AIST have served as chairs, secretaries and conveners, 258 researchers have participated in meetings of those organizations as experts. ${ }^{[10]}$

In terms of standardization, the research conducted at AIST includes the following topics:

1. Environmental analysis methods of hazardous chemicals; ${ }^{[11]}$

2. Production and utilization of thermophysical property data; ${ }^{[12]}$

3. High pressure gaseous hydrogen $;^{[13]}$

4. Four dimensional radiotherapy system $;{ }^{[14]}$

5. Secure password authentication schemes, ${ }^{[15]}$

6. Methodology for designing cryptographic systems; ${ }^{[16]}$

7. Utilization of thermophysical property data; ${ }^{[17]}$

8. SOFC systems, ${ }^{[18]}$

9. Font size for elderly people, ${ }^{[19]}$

10. SOFC cell/stack power generation performance tests, ${ }^{[20]}$

11. Utilization of observational data; ${ }^{[2]]}$

12. Analysis method for oxygen impurity in magnesium and its alloys; ${ }^{[22]}$

13. Automotive navigation and route guidance system; ${ }^{[23]}$

14. Thermoelectric hydrogen gas sensor, ${ }^{[24]}$ 
15. Safe usage of moving images, ${ }^{[25]}$

16. Evaluation device of cosmetics for UV protection; ${ }^{[26]}$

17. Cryptographic modules; ${ }^{[27]}$

18. Three-dimensional shape for supporting industry; ${ }^{[28]}$

19. Geological map; ${ }^{[29]}$

20. Accessible design for senior citizens. ${ }^{[30]}$

However, these studies mainly focus on the formation process of standardization (pre-standards' formation), without consideration of the management of standards after their formation is completed (post-standards' formation). In our study, we also present a roadmap to innovation after the standards' formation is completed so as to integrate R\&D results and standardization activities more effectively and comprehensively. This knowledge could improve the results of R\&D in social settings, reducing their management costs and increasing efficiency.

In Japan, de jure standards are prepared by the Japanese Industrial Standards Committee (JISC). Such standards are reviewed every 5 years to decide whether standards are to be terminated, revised, or continued. The review interval has been fixed to a 5-year period, regardless of technological differences for several decades. However, some standards may not need to be reviewed so often. Previous studies did not show the distribution of the lifespan of each standard and this led to a fixed review interval. If the statistical evidence regarding the lifespan of standards is provided, a more appropriate review interval can be considered, following the academic evidence. We can use the knowledge of the lifespan for the international standardization organizations such as ISO since ISO also has been using the fixed interval review system for several decades.

Producing new standards and then maintaining them requires both human and financial resources. Under the current JISC rules, standards are reviewed every 5 years. Is the fixed 5 -year review interval the most adequate, in a scientific perspective? This is the fundamental research question of this study. Our results show that the standards in specific technological categories tend to have longer lifespans. These standards can be revised to make their review periods longer.

For the sake of this study, the lifespan, defined as the number of years between the establishment of a standard and its end, was the dependent variable in our model. Several factors supposed to be related to the lifespan are used for statistical analysis. Specifically, the following factors are considered: 1) technological category; 2) relationship with an international standard; 3) legal status (e.g., whether the standard has been incorporated into legislation yet); 4) revisions (e.g., revision of contents); and 5) type of standard. The relationship among these variables is defined as follows:

Lifespan of standard = $\mathrm{f}$ (technological category, relationship with an international standard, legal status, revision, type of standard).

Technological category is supposed to have a relationship with lifespans because the product lifecycle (e.g., technology lifecycle) is related to the lifespan of standards. In addition, international standards are supposed to have an effect on lifespans because changes in an international standard, such as a standard of the ISO or IEC, can lead to corresponding amendments in the JIS system. The revision status of a standard may have a relationship with lifespans because revisions are presumed to lead to a renewal of the technology targeted by the standard. The type of standards may also have a relationship with lifespans because the production standards will no longer be necessary once a product has left the market.

For the sake of this study, the e-JISC, the electric database of reference for METI, was used. This database is used for administrative purposes, and it has been used for this type of analysis for the first time in this paper.

In this study, about 4500 JIS are surveyed. Our major contributions are as follows:

1) The lifespans of JIS in each technological category is first investigated and the data we obtained are shown in figures;

2) We found statistically significant differences in the marginal effects of technological categories on lifespans. As a result, the standards of certain technological sectors are observed to have longer lifespans than others. This evidence leads to support a flexible interval system;

3) Based on our results, we proposed a road map scenario 
to improve national innovation systems through the management of standards.

\section{Literature review and hypothesis formation}

\subsection{Management of standards}

The existing research on the management of standards is mainly focused on how to form standards. ${ }^{[31]}$ How to manage already formed standards in terms of innovation systems has not been recognized as a fundamental research topic so far, for the following reasons:

1) The formation of standards is still the main interest among researchers and research on the management of standards is still in its introductory phase;

2) Lack of available data for the purpose of standards' research. ${ }^{[32]}$

\subsection{JIS preparation process}

JIS are mainly prepared to meet the needs of the private sector. Around $80-90 \%$ of JIS are newly established or revised as a consequence of proposals from the private sector under Article 12 of the Industrial Standardization Act. ${ }^{[33]}$ In the formation process of standards, a draft for the JIS is prepared by a group of interest. This draft is then submitted to a drafting committee whose participants are drawn from producers, users, and third parties. If this step is successful, then, as the next step, the confirmed draft is sent to JISC. Finally, JISC deliberates about the draft and the standard may be authorized. ${ }^{[34]}$

\subsection{Effective terms of de facto standards}

Several studies have focused on the effective terms of de facto standards, but they do not include de jure standards in their scope. Known as the most famous case study on the effective terms of de facto technology standards, David ${ }^{[35]}$ investigates the standard of QWERTY typewriters. In his research, it was noted that such technology standards lasted for about 100 years without revision, not even after more efficient keyboard arrangements were developed. The key arrangement that was first developed is not the most efficient arrangement possible and was, in fact, designed to reduce typing speed. This feature of the design was important at the time of its introduction about 100 years ago because the typing speed of humans was faster than the mechanical capabilities of typewriters.
Today, nearly all typewriters have been replaced by personal computers. Inputs can even be provided to personal computers through a virtual touch screen keyboard instead of a physical keyboard. Hence, replacing the arrangement of keyboards would improve efficiency. Nevertheless, the QWERTY keyboard layout is still in use, even in touch screen interfaces. This case shows a lock-in effect, strong enough to effectively prevent changes in the basic interface of personal computers. David used this case to illustrate the persistency of standards. ${ }^{[35]}$

Another case study focusing on de facto standards in the fields of audio-visual and information technologies was conducted by Yamada. ${ }^{[36]}$ This research showed that a de facto standard is established when the market share of a product reaches $2 \%-3 \%$. David's research explained the persistency of standards in terms of a lock-in effect, focusing on human learning, but not all factors related to market dynamics were analyzed. Yamada's research gives some guidelines about the timing of formation for de facto standards, but not all determinants other than market share were discussed. In both cases, the focus is on de facto standards.

Although these studies discussed the effective terms of standards, they did not normatively discuss a scenario to improve the management system of standards, depending on their research results. Our study suggests a way to improve innovation systems through the effective management of standards.

\subsection{Other related research}

There are several related studies to be taken into account.

\subsubsection{International standards}

The relationship between international standards and international trade flows was studied by Blind and Jungmittach. ${ }^{[37]}$ As for the consistency between JIS and international standards, about 6,000 of the 10,000 JIS were related to international standards. ${ }^{[33]}$ Harmonizing with international standards has become more important after the introduction of the World Trade Organization's Technical Barriers to Trade (TBT) agreement in 1995. Since then, JISC has been promoting consistency between JIS and international de jure standards, such as those published by the ISO and IEC. However, the relationship between the JIS lifespan and 
international standards has not been studied yet, even after the TBT enforcement. We control for this effect in the evaluation of the influence of the technological categories.

\subsubsection{Legal usage}

JIS are used in some laws and regulations, such as the Pharmaceutical Affairs Act, the Fire Service Act, and the Human Resource Development Promotion Act in Japan. JIS are cited around 6,500 times in the Japanese law. ${ }^{[33]}$ Nevertheless, the relationship between legal citations and JIS lifespans has not been studied previously. We control for this effect in the evaluation of the influence of technological categories.

\subsection{Selection of relevant elements}

\subsubsection{Overview}

The purpose of this study is to find a way to improve the management of standards. For this purpose, we need to identify which technological category influences the lifespan of standards. In addition, we need to introduce a set of control variables.

In this study, the hypothesis that technological category effects the lifespan of standards is formulated and examined through statistical estimation. The economic value of standards can be measured in several ways. Lifespan is a way of assessing their value. Under JISC rules, JIS are reviewed every 5 years; in the review, it is decided whether to terminate a standard or not, taking into account the opinion of the related industrial sector. This means that, if a standard does not seem to be needed in the 5-year review, such standards will be terminated. In this research, the lifespan of a standard is used as a proxy for the economic value of standards.

Although details vary across technological categories, the lifespan of a standard is supposed to be related to a certain stage in the product life cycle. When a product leaves the market, the related standard is supposed to be terminated. Each standard is associated with a specific technological category. In the JIS classification scheme, there is a category for management standards. Management standards are rulerelated standards that are used in organizations and in society as a whole. This research includes management standards within the scope of its analysis.

\subsubsection{Control variables}

\subsubsection{International standard}

Some JIS were prepared on the basis of international standards to ensure standards to be domestically and internationally harmonized. In this analysis, "international standards" refers to ISO and IEC standards. When an international standard is converted into JIS, it is likely that there will be both positive and negative effects on the lifespan. The contents of the associated international standards are used in more areas and countries than in the case of JIS. Hence, the relationship with an international standard tends to produce a strong lock-in effect, and the standard is less likely to be terminated. Because of this, the lifespan of lockedin standards will tend to be longer. To control for this effect on the lifespan, a variable related to international standards needs to be included in the estimation of the model.

\subsubsection{Legal usage}

Some standards have legal effects, and one of the important roles of JIS is to provide national rules for Japan, where JIS represent the de jure set of standards. Some laws use JIS for quantitative regulation and for reference. As such, this usage requires stability, to be in line with the regulative purpose, hoping that such standards will stay in force. In addition, to change laws and administrative rules that are based on JIS, a formal process, typically involving Congress or the Cabinet, is needed. As a result, JIS in legal usage are usually thought to have a longer lifespan. To control for this effect on lifespan, a variable related to legal usage needs to be included in the model.

\subsubsection{Revision}

The revision of standards is likely to extend their lifespan because, when revisions are made, technological progress is incorporated into the revised standards. Hence, technological progress will be reflected in the contents of such standards, and, therefore, a revision should extend the lifespan of a standard. To control for this effect on lifespan, a variable related to revision needs to be included in the model.

\subsubsection{Type of standard}

The type of a standard may be related to its lifespan. For example, in the case of measurement standards, the described measurement method may be used to gather information about the quality of products. However, the need for standards 
concerning specific products will diminish as those products leave the market. Hence, measurement standards seem, in general, to be useful over a longer span than product-related standards. Nevertheless, it is also possible to conceive a relationship in the opposite direction. In industries where radical innovation is more frequent than incremental innovation, innovation in products and measurement cannot lag behind. Thus, innovation in products and measurement will happen together. When an obsolete product leaves the market, the associated measurement methods will also leave the market. In such industries, measurement standards may have lifespans similar to those of product standards. This means that technological replacement will be associated with the replacement of measurement methods. In short, in industrial sectors with frequent and radical innovations, measurement standards will be less static. For example, when digital media such as CDs (compact discs) were introduced, the technology related to analog storage media (like LP records) disappeared from the market. To control for this effect on the lifespan, a variable related to the type of standards needs to be included in the model. In addition to the categories such as 1) product and 2) measurement, there is the type of standards, which relate to a design and a mark. We formulate standards of the design and mark.

\subsection{Hypothesis}

To evaluate the effect of technological categories, we control for the above-mentioned elements. The following hypothesis is used in this study for the empirical analysis and scenario formation:

Hypothesis (H). The technological category of a standard affects positively or negatively the lifespan of a standard.

\section{Method and Models}

In this study, the relationship among the above-mentioned elements is statistically analyzed.

\subsection{Model formation}

We estimate the following regression to show the relationship among relevant elements and test the above-mentioned hypothesis. The dependent variable in the models is the lifespan, measured in years.

$$
\begin{aligned}
& \text { Model1: LIF }=\text { constant }+\sum_{i=1}^{18} \beta i T E C i \\
& + \text { control variables }+u,
\end{aligned}
$$

where the following is referred:

control variables: ISO, LEG, REV, ESY, and ENY

LIF: lifespan of a standard;

TEC: category of a standard (dummy);

ISO: international standard status (dummy);

LEG: legal status (dummy);

REV: revision (dummy);

ESY: establishment year of a standard (ten-year interval categories (dummy));

ENY: end year of a standard (ten-year interval categories (dummy));

constant: constant term; and

$\mathrm{u}$ : error term.

In addition, to check the robustness of Model 1, we formulate Model 2, in which the type of standards is added as a control variable. In Model 2, to evaluate the effect of the type of standards (e.g., a) production; b) measurement; c) design and mark), we add an additional control variable (dummy variable), as follows:

$$
\begin{aligned}
& \text { Model2: LIF }=\text { constant }+\sum_{\mathrm{i}=1}^{18} \beta i T E C i \\
& + \text { control variables }+u,
\end{aligned}
$$

where control variables include ISO, LEG, REV, ESY, ENY, and TOS, and TOS is a dummy variable for the type of standards. All other variables are the same as in Model 1.

\subsection{Method}

The ordinary least squares (OLS) analysis is used to estimate the coefficients of both models and to test our hypothesis. The statistical package STATA is used for the estimation.

\subsubsection{Dataset}

In this study, we used data from the e-JISC, the electric database of reference for the METI officials. The e-JISC provides data including the information of the JIS Handbook. ${ }^{[38]}$ For example, besides the contents of each standard presented in the JIS Handbook, the e-JISC provides data relating to JIS, such as, 1) starting time; 2) ending time; 3) amendment time; 4) title; 5) identification number in a database format. Currently, the e-JISC is prepared and maintained by METI and used for administrative purposes. 
For this research, we used the database under the academic cooperation between METI and RIETI (Research Institution of Economy, Trade and Industry). In this study, we use such information to build a new data set and we conduct a comprehensive analysis of the JIS lifespan for the first time.

At present, around 12,000 JIS are in effect, and in the past about 7,600 have been ended. Only standards for which complete data are available were chosen. We ended up with 4,483 standards (observations). We first analyzed the lifespan distribution in each technological category. The distributions are presented in Fig. 1. The distribution of the lifespan of standards varies across technological categories.

\subsubsection{Variables}

A detailed explanation of each variable is reported in Table 1. The categories specified in JIS were used as technological categories in our models, and dummy variables were introduced for each category in Table 2. The type of standards was determined from the description in the title of each standard, and categorized into 1) product; 2) measurement; and 3) design and mark. Dummy variables for the time when each standard was established (beginning) and the time when each standard was terminated (ending) were introduced, using ten-year intervals.

The dependent variable in the models is lifespan, measured in years. As shown in Table 2, we introduce the variables "cl" to "c19" corresponding to the technological categories of JIS. The variable "iso_iec" indicates the relationship with international standards. The variable "legal" indicates the use of a standard in legislation or for regulatory purposes. The variable "re" indicates whether a standard has been revised or not. For the purpose of controlling for the generation effect, we introduce the dummy variables "year10b\#" and "year10e\#" (where \# represents an index), which represent the introduction and end years of a standard, respectively.

Among the categorical variables, $\mathrm{cl}$ "A: Civil engineering and architecture" (technological category), year10b1 (starting year), year10e1 (ending year), and p_type (type of standard) are used as baseline categories for the empirical estimation. "A: Civil engineering and architecture" was selected as the default industrial category due to its adequate number of observations.

\section{Results and discussion}

Table 3 shows the descriptive statistics for all variables. The OLS regression results are shown in Table 4.

In Model 1, looking at the coefficient on the industrial sector, the categories (c8) "H: Non-ferrous materials and metallurgy" and (c13) "Q: Management system" are not statistically significant. The categories (c11) "M: Mining" and (c15) "S: Domestic wares" show a tendency to be significant $(p<0.10)$. The other sectors' coefficients are all statistically significant. This result supports our hypothesis. Only the category (c17) "W: Aircraft and aviation" shows a negative coefficient, although this is relative to that of the baseline category (c1) "A: Civil engineering and architecture." In Model 2, we use the type of standards as a control variable to check the robustness of the results of Model 1. In both Model 1 and Model 2, the significance of the results is the same. From the above results, the model is rewritten as

Lifespan of standard $=\mathrm{f}($ technological category $(+/-))$

Standards are reviewed at 5-year intervals, but those standards that are likely to have a longer lifespan would benefit from longer review intervals. Among all technological categories, those with larger coefficients tend to have longer lifespans. Coefficients larger than 2 are highlighted in Table 5, and include (c6) "F: Shipbuilding" and (c2) "B: Mechanical engineering." In terms of sectors showing a shorter lifespan, (c17) "W: Aircraft and aviation" is statistically significant, but the coefficient is about -1 , which is not large in this context. The difference in the coefficients between the two industrial categories does not seem large enough to suggest shortening the review period.

As for the theoretical model of the lifespan of the standards in the dynamic innovation process, transitions to newer technologies occur after the market for a prevailing technology is saturated, and new standards are required corresponding to the emergence of new markets. ${ }^{[39]-[41]}$ Repetition of the sequence generates sequential innovation. The observed result empirically shows that the time-series behavior of the innovation processes differs according to technological categories. 


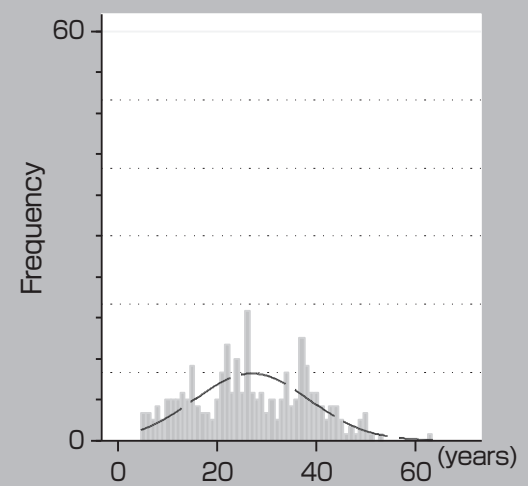

A: Civil engineering and architecture

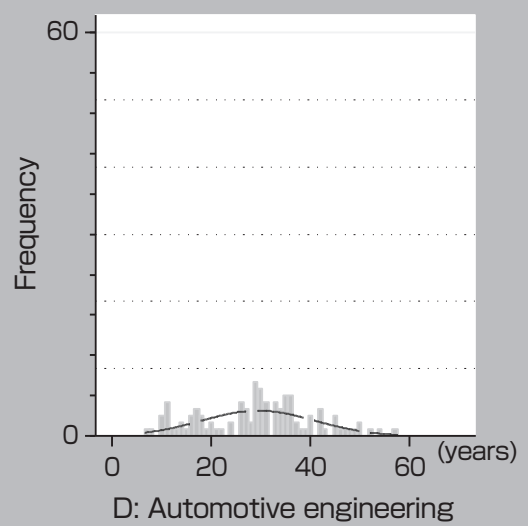

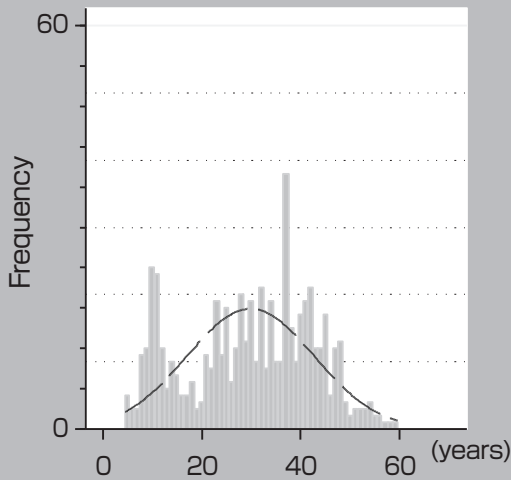

B: Mechanical engineering

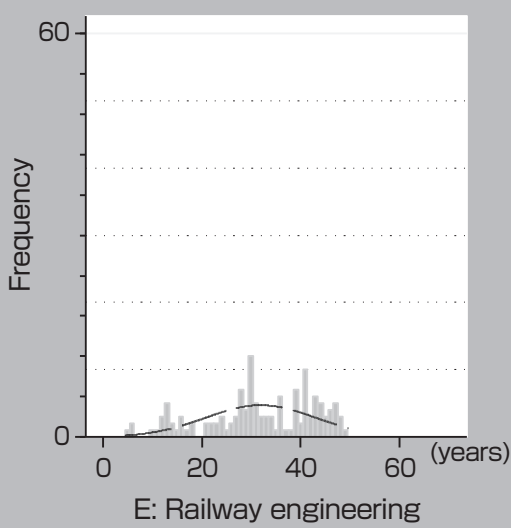

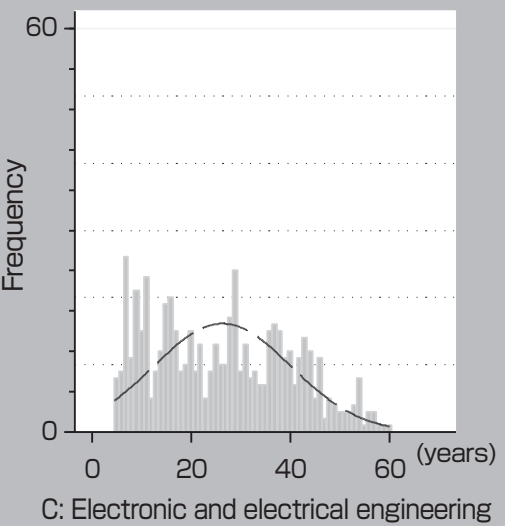

C: Electronic and electrical engineering
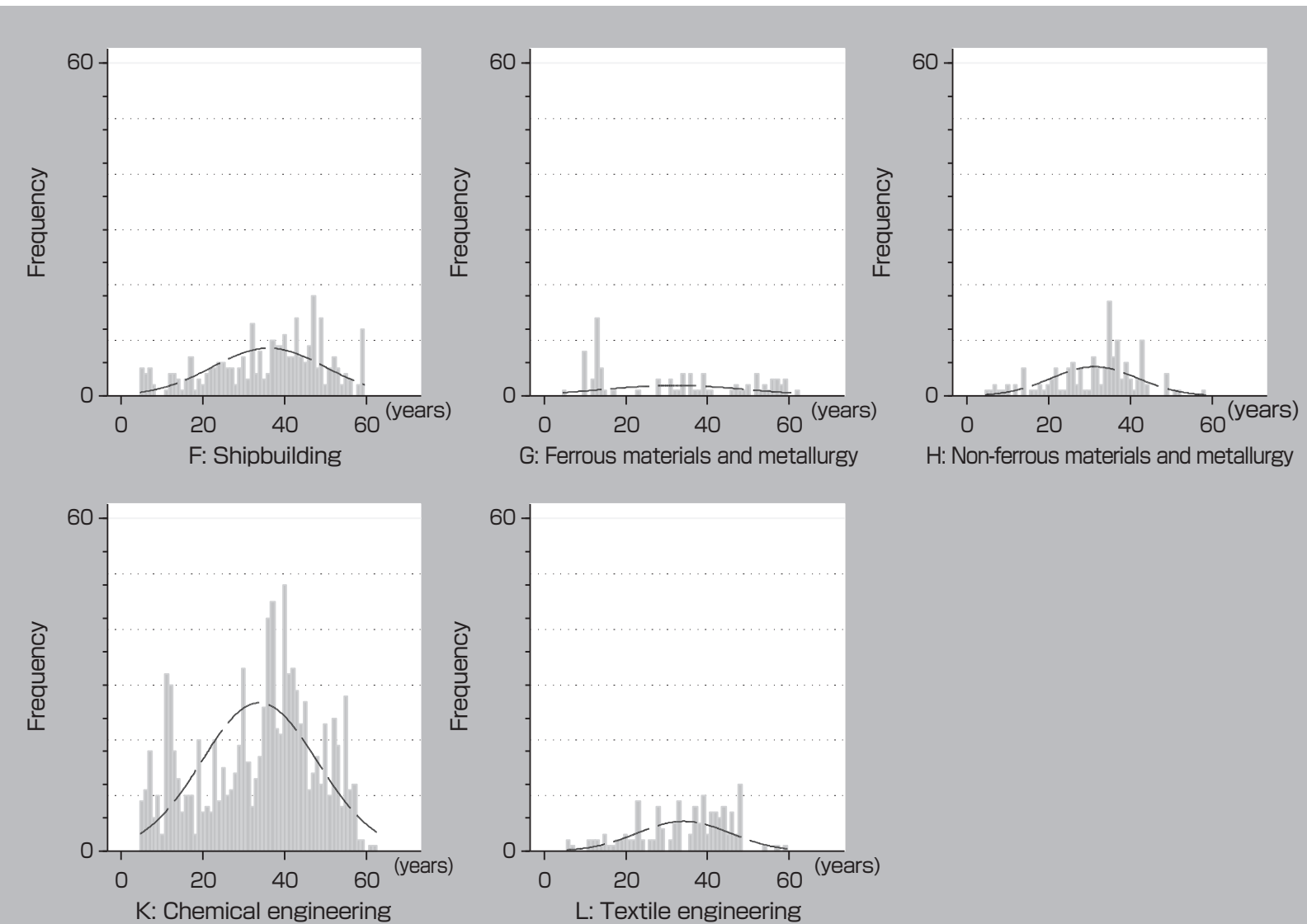

Fig. 1 Lifespan distribution of JIS standards 

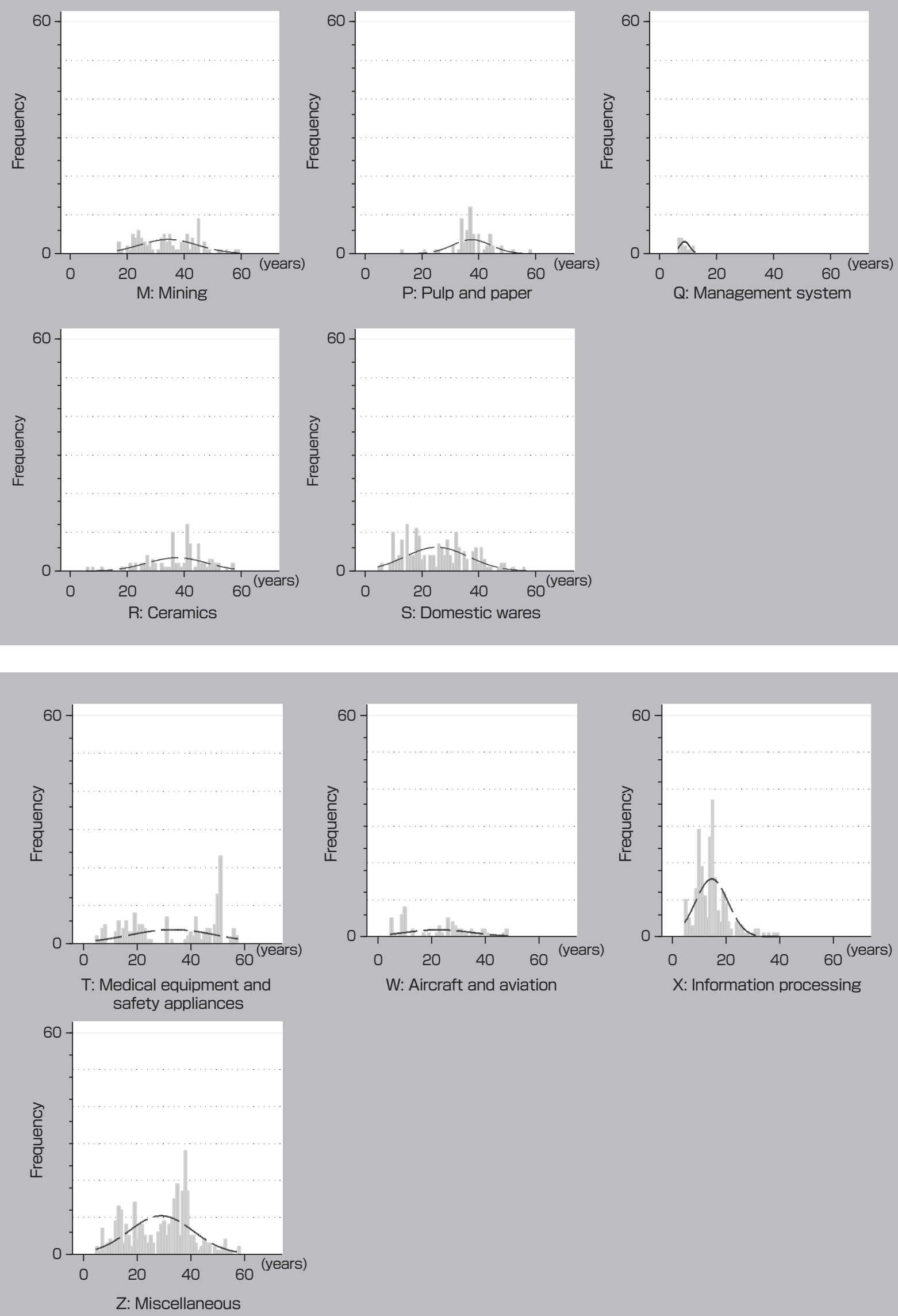

Fig. 1 Lifespan distribution of JIS standards 
Table 1. Explanation of variables

\begin{tabular}{|c|c|c|c|c|}
\hline Variable & $\begin{array}{c}\text { Notation in } \\
\text { analytical results }\end{array}$ & Explanation & Source & Notes \\
\hline LIF & lif & $\begin{array}{l}\text { Lifespan of standard : The number of years } \\
\text { while the standard have been in place }\end{array}$ & $\begin{array}{l}\text { Data from Japanese Standards } \\
\text { Association (201 1) and JISC data }\end{array}$ & Dependent variable \\
\hline TEC & c1, c2, c3, $\cdots$, c19 & $\begin{array}{l}\text { Technological category: Dummy variable for } \\
\text { technological category }\end{array}$ & $\begin{array}{l}\text { Data from Japanese Standards } \\
\text { Association (2011) and JISC data }\end{array}$ & Independent variable \\
\hline ISO & iso_iec & $\begin{array}{l}\text { International standardization: Dummy } \\
\text { variable for international standardization }\end{array}$ & $\begin{array}{l}\text { Data from Japanese Standards } \\
\text { Association (2011) and JISC data }\end{array}$ & $\begin{array}{l}\text { Independent variable } \\
\text { Control variable }\end{array}$ \\
\hline LEG & legal & Legal status: Dummy variable for legal usage & $\begin{array}{l}\text { Data from Japanese Standards } \\
\text { Association (2011) and JISC data }\end{array}$ & $\begin{array}{l}\text { Independent variable } \\
\text { Control variable }\end{array}$ \\
\hline REV & re & Revision: Dummy variable revised or not & $\begin{array}{l}\text { Data from Japanese Standards } \\
\text { Association (2011) and JISC data }\end{array}$ & $\begin{array}{l}\text { Independent variable } \\
\text { Control variable }\end{array}$ \\
\hline ESY & year 10b\# & $\begin{array}{l}\text { Established year: The year when a standard } \\
\text { is formed (ten year categorization basis; "\#" } \\
\text { is group number.) }\end{array}$ & $\begin{array}{l}\text { Data from Japanese Standards } \\
\text { Association (2011) and JISC data }\end{array}$ & $\begin{array}{l}\text { Independent variable } \\
\text { Control variable }\end{array}$ \\
\hline ENY & year 10e\# & $\begin{array}{l}\text { End year: The year when a standard is } \\
\text { terminated (ten year categorization basis; } \\
\text { "\#" is group number.) }\end{array}$ & $\begin{array}{l}\text { Data from Japanese Standards } \\
\text { Association (2011) and JISC data }\end{array}$ & $\begin{array}{l}\text { Independent variable } \\
\text { Control variable }\end{array}$ \\
\hline TOS & $\begin{array}{l}\text { p_type, } \\
\text { m_type } \\
\text { d_type }\end{array}$ & $\begin{array}{l}\text { Type of standard: Dummy variable for } \\
\text { standard category: i) "d_type" indicates a } \\
\text { design and mark standard; ii) "m_type" } \\
\text { indicates a measurement standard; iii) "p_type" } \\
\text { indicates a production standard. }\end{array}$ & $\begin{array}{l}\text { Data from Japanese Standards } \\
\text { Association (201 1) and JISC data }\end{array}$ & $\begin{array}{l}\text { Independent variable } \\
\text { Control variable }\end{array}$ \\
\hline
\end{tabular}

Table 2. Alphabetic JIS technology code and technology area name

\begin{tabular}{|c|c|}
\hline $\begin{array}{c}\text { Alphabetic JIS technology code and } \\
\text { technology area name }\end{array}$ & $\begin{array}{l}\text { Corresponding } \\
\text { independent } \\
\text { dummy variable } \\
\text { in models } 1 \text { and } 2\end{array}$ \\
\hline A: Civil engineering and architecture & C 1 \\
\hline B: Mechanical engineering & $\mathrm{c} 2$ \\
\hline C: Electronic and electrical engineering & c3 \\
\hline D: Automotive engineering & c4 \\
\hline E: Railway engineering & c5 \\
\hline F: Shipbuilding & c6 \\
\hline G: Ferrous materials and metallurgy & c7 \\
\hline $\mathrm{H}$ : Non-ferrous materials and metallurgy & c8 \\
\hline K: Chemical engineering & c9 \\
\hline L: Textile engineering & c10 \\
\hline M: Mining & c11 \\
\hline P: Pulp and paper & c12 \\
\hline Q: Management system & c13 \\
\hline R: Ceramics & c14 \\
\hline S: Domestic wares & c15 \\
\hline T: Medical equipment and safety appliances & c16 \\
\hline W: Aircraft and aviation & c17 \\
\hline X: Information processing & c18 \\
\hline Z: Miscellaneous & c19 \\
\hline
\end{tabular}


Table 3. Descriptive statistics of variables

\begin{tabular}{|c|c|c|c|c|c|}
\hline Variable & Obs & Mean & Std.Dev. & Min & Max \\
\hline \multicolumn{6}{|l|}{ 1.Independent variable } \\
\hline lif & 4483 & 30.01115 & 13.75334 & 5 & 63 \\
\hline \multicolumn{6}{|l|}{ 2.Dependent variable } \\
\hline$c 7$ & 4483 & 0.06402 & 0.244815 & 0 & 1 \\
\hline$c 2$ & 4483 & 0.128485 & 0.334667 & 0 & 1 \\
\hline c3 & 4483 & 0.125139 & 0.330914 & 0 & 1 \\
\hline$c 4$ & 4483 & 0.024091 & 0.153349 & 0 & 1 \\
\hline c5 & 4483 & 0.029445 & 0.169068 & 0 & 1 \\
\hline$c 6$ & 4483 & 0.066473 & 0.249136 & 0 & 1 \\
\hline$c 7$ & 4483 & 0.018961 & 0.136401 & 0 & 1 \\
\hline$c 8$ & 4483 & 0.031229 & 0.173956 & 0 & 1 \\
\hline$c 9$ & 4483 & 0.211912 & 0.408708 & 0 & 1 \\
\hline$c 10$ & 4483 & 0.034352 & 0.182152 & 0 & 1 \\
\hline cll & 4483 & 0.020968 & 0.143294 & 0 & 1 \\
\hline c12 & 4483 & 0.013607 & 0.115866 & 0 & 1 \\
\hline$c 13$ & 4483 & 0.003123 & 0.055802 & 0 & 1 \\
\hline c14 & 4483 & 0.020299 & 0.141037 & 0 & 1 \\
\hline c15 & 4483 & 0.038367 & 0.192103 & 0 & 1 \\
\hline c16 & 4483 & 0.033906 & 0.181007 & 0 & 1 \\
\hline c17 & 4483 & 0.013384 & 0.114925 & 0 & 1 \\
\hline$c 18$ & 4483 & 0.052866 & 0.223792 & 0 & 1 \\
\hline$c 19$ & 4483 & 0.069373 & 0.254116 & 0 & 1 \\
\hline \multicolumn{6}{|l|}{ Control Variable } \\
\hline iso_iec & 4483 & 0.152353 & 0.359403 & 0 & 1 \\
\hline legal & 4483 & 0.003569 & 0.059641 & 0 & 1 \\
\hline re & 4483 & 0.71131 & 0.453288 & 0 & 1 \\
\hline d_type & 4483 & 0.009146 & 0.095205 & 0 & 1 \\
\hline$m_{-}$type & 4483 & 0.167076 & 0.373085 & 0 & 1 \\
\hline p_type & 4483 & 0.823779 & 0.381051 & 0 & 1 \\
\hline year $10 b 1$ & 4483 & 0.002454 & 0.04948 & 0 & 1 \\
\hline year $10 b 2$ & 4483 & 0.348204 & 0.476454 & 0 & 1 \\
\hline year $10 b 3$ & 4483 & 0.227303 & 0.419137 & 0 & 1 \\
\hline year $10 b 4$ & 4483 & 0.158822 & 0.365551 & 0 & 1 \\
\hline year $10 b 5$ & 4483 & 0.119563 & 0.324486 & 0 & 1 \\
\hline year $10 b 6$ & 4483 & 0.107963 & 0.310369 & 0 & 1 \\
\hline year $10 b 7$ & 4483 & 0.03569 & 0.185538 & 0 & 1 \\
\hline year $10 e 1$ & 4483 & 0.05242 & 0.222898 & 0 & 1 \\
\hline year $10 e 2$ & 4483 & 0.498996 & 0.500055 & 0 & 1 \\
\hline year $10 e 3$ & 4483 & 0.326121 & 0.468844 & 0 & 1 \\
\hline year $10 e 4$ & 4483 & 0.122463 & 0.327856 & 0 & 1 \\
\hline
\end{tabular}


Table 4. Estimation results

\begin{tabular}{|c|c|c|}
\hline \multicolumn{3}{|c|}{ Dependent variable: lif } \\
\hline Independent variable & $\begin{array}{c}\text { model } 1 \\
\text { (coefficient/t-value) }\end{array}$ & $\begin{array}{c}\text { model2 } \\
\text { (coefficient/t-value) }\end{array}$ \\
\hline \multicolumn{3}{|l|}{ 1.Technological category } \\
\hline$c 2$ & $\begin{array}{c}2.0567 \\
{[7.30]^{* * *}}\end{array}$ & $\begin{array}{l}2.0542 \\
{[7.28]^{* * *}}\end{array}$ \\
\hline c3 & $\begin{array}{c}1.1003 \\
{[3.86]^{* * *}}\end{array}$ & {$[3.84]^{* * *}$} \\
\hline$c 4$ & [2.75]*** & {$[2.74]^{* * *}$} \\
\hline$c 5$ & $\begin{array}{l}1.1824 \\
{[2.91]^{* * *}}\end{array}$ & $\begin{array}{l}1.1844 \\
{[2.91]^{* * *}}\end{array}$ \\
\hline$c 6$ & 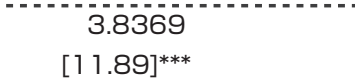 & 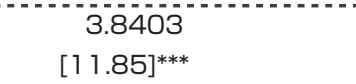 \\
\hline$c 7$ & {$[4.63]^{* * *}$} & {$[4.64]^{* * *}$} \\
\hline c8 & {$[0.63]$} & $\begin{array}{l}0.2551 \\
{[0.64]}\end{array}$ \\
\hline$c 9$ & {$[5.57]^{* * *}$} & {$[5.58]^{* * *}$} \\
\hline$c 10$ & {$[5.88]^{* * *}$} & $\begin{array}{c}2.298 \\
{[5.89]^{* * *}}\end{array}$ \\
\hline Cl1 & {$[1.91]^{*}$} & {$[1.90]^{*}$} \\
\hline c12 & {$[4.95]^{* * *}$} & $\begin{array}{l}2.7002 \\
{[4.92]^{* * *}}\end{array}$ \\
\hline c13 & $\begin{array}{l}-1.1582 \\
{[-1.08]}\end{array}$ & $\begin{array}{l}-1.158 \\
{[-1.08]}\end{array}$ \\
\hline c14 & {$[2.88]^{* * *}$} & {$[2.86]^{* * *}$} \\
\hline c15 & $\begin{array}{l}0.6355 \\
{[1.70]^{*}}\end{array}$ & $\begin{array}{l}0.6399 \\
{[1.71]^{*}}\end{array}$ \\
\hline$c 16$ & $\begin{array}{l}2.0533 \\
{[5.15]^{* * *}}\end{array}$ & $\begin{array}{l}2.057 \\
{[5.15]^{* * *}}\end{array}$ \\
\hline c17 & $\begin{array}{l}-1.3009 \\
{[-2.36]^{* *}}\end{array}$ & - 1.2956 \\
\hline$c 18$ & $\begin{array}{l}1.0596 \\
{[2.83]^{* * *}}\end{array}$ & $\begin{array}{l}1.0524 \\
{[2.78]^{* * *}}\end{array}$ \\
\hline$c 19$ & $\begin{array}{l}1.2459 \\
{[3.90]^{* * *}}\end{array}$ & $\begin{array}{l}1.2466 \\
{[3.90]^{* * *}}\end{array}$ \\
\hline constant & $\begin{array}{c}35.6928 \\
{[29.04]^{* * *}}\end{array}$ & $\begin{array}{c}35.6594 \\
{[28.98]^{* * *}}\end{array}$ \\
\hline \multicolumn{3}{|l|}{ 2.Control variable } \\
\hline ISO & yes & yes \\
\hline LEG & yes & yes \\
\hline REV & yes & yes \\
\hline ESY & yes & yea \\
\hline ENY & yes & yes \\
\hline TOS & no & yes \\
\hline $\begin{array}{l}\text { R-squared } \\
\text { Adj-R-squared } \\
\mathrm{N}\end{array}$ & $\begin{array}{r}0.9231 \\
0.9226 \\
4483\end{array}$ & $\begin{array}{r}0.9231 \\
0.9225 \\
4483\end{array}$ \\
\hline $\begin{array}{l}\text { NOTE: [ ] t-value, }{ }^{*} \mathrm{p}<0.1 \text {, } \\
\text { Control variables: } 1 \text { )internati } \\
\text { year(ESY) and 5)end year(EN }\end{array}$ & $\begin{array}{l}0.01 . \\
\text { n(ISO), 2)legal status(LEG) } \\
\text { Doth models. Type of standal }\end{array}$ & $\begin{array}{l}\text { (REV), 4)established } \\
\text { only included in the model2. }\end{array}$ \\
\hline
\end{tabular}


Table 5. Technology categories and coefficients

\begin{tabular}{|c|c|c|c|c|}
\hline & $\begin{array}{l}\text { Positive } \\
\text { coefficient } \\
\text { (Model } 1 / \\
\text { Model 2) }\end{array}$ & $\begin{array}{l}\text { Negative } \\
\text { coefficient } \\
\text { (Model 1 } 1 / \\
\text { Model 2) }\end{array}$ & $\begin{array}{l}\text { Significant level } \\
\text { (Model } 1 / \\
\text { Model 2) }\end{array}$ & Notes \\
\hline A: Civil engineering and architecture & & & & $\begin{array}{l}\text { Cl (Base } \\
\text { group) }\end{array}$ \\
\hline B: Mechanical engineering & 2.05/2.05 & & $* * * / * * *$ & $\mathrm{c} 2$ \\
\hline C: Electronic and electrical engineering & $1.10 / 1.09$ & & $* * * / * * *$ & c3 \\
\hline D: Automotive engineering & $1.20 / 1.20$ & & $* * * / * * *$ & c4 \\
\hline E: Railway engineering & $1.18 / 1.18$ & & $* * * / * * *$ & c5 \\
\hline F: Shipbuilding & 3.83/3.84 & & $* * * / * * *$ & c6 \\
\hline G: Ferrous materials and metallurgy & 2.27/2.27 & & $* * * / * * *$ & c7 \\
\hline $\mathrm{H}$ : Non-ferrous materials and metallurgy & & & & c8 \\
\hline $\mathrm{K}$ : Chemical engineering & $1.48 / 1.49$ & & $* * * / * * *$ & c9 \\
\hline L: Textile engineering & 2.29/2.29 & & $* * * / * * *$ & c10 \\
\hline M: Mining & $0.88 / 0.87$ & & $* / *$ & c 11 \\
\hline P: Pulp and paper & 2.69/2.70 & & $* * * / * * *$ & c12 \\
\hline Q Management system & & & & c13 \\
\hline R: Ceramics & $1.34 / 1.33$ & & $* * * / * * *$ & c14 \\
\hline S: Domestic wares & $0.63 / 0.63$ & & $* / *$ & c15 \\
\hline T: Medical equipment and safety appliances & 2.05/2.05 & & $* * * / * * *$ & c16 \\
\hline W: Aircraft and aviation & & $-1.30 /-1.29$ & $* * / * *$ & c 17 \\
\hline $\mathrm{X}$ : Information processing & $1.05 / 1.05$ & & $* * * / * * *$ & c 18 \\
\hline Z: Miscellaneous & $1.24 / 1.24$ & & $* * * / * * *$ & c19 \\
\hline
\end{tabular}

Note: Coefficients with absolute value greater than 2 are highlighted. $\left({ }^{*} \mathrm{p}<0.1,{ }^{* *} \mathrm{p}<0.05,{ }^{* * *} \mathrm{p}<0.01\right)$ 


\section{Future scenario and policy implications}

In Fig. 2, we present a road map scenario for the future development and further integration of the elements presented. We propose a scenario that covers both short-term and longterm outcome goals. The current scenario, as implicitly shown in AIST research, only focuses on a short-term scenario. Our scenario includes both pre-standardization and poststandardization management, while the current roadmap includes only pre-standardization management of invented technology. Moreover, the pre-standardization management mainly focuses on the R\&D perspectives. Today, standards play an important role and, in some cases, standards are essential for the formation of new product markets. Standards play an important role in the dynamic change of the product life cycle. Innovation and standards are complementary to each other. ${ }^{[39]-[41]}$ Previous research mainly discussed the first stage of the proposed scenario " 1 . R\&D and standardization." In this study, we show that we can improve the scenario focusing on "2. Integration of relevant elements." Knowing that lifespan varies across technological categories, we can improve the management system of standards, focusing on the post-standardization phase. As a result, we can introduce a third stage " 3 . Improvement of the management system of standards," achieving more effective management systems for the established standards and timely market creation, and obtain "4. Improvement of the innovation system," which means the establishment of a platform for the management of standards for innovation systems.
We suggest the possibility to reduce the administrative cost of maintaining standards simply by allowing longer review intervals of standards. This is the key feature of the proposed stage "3. Improvement of the management system of standards." The current interval of 5 years could be extended for some categories, as suggested by the coefficients in our estimation results. The results from Models 1 and 2 suggest that the following industrial categories are ideal candidates for less frequent reviews: (c2) "B: Mechanical engineering;" (c6) "F: Shipbuilding;" (c7) "G: Ferrous materials and metallurgy;" (c10) "L: Textile engineering;" (c12) "P: Pulp and paper;" (c16) “T: Medical equipment and safety appliances.” De jure standards are prepared and used across both developed countries and developing countries, even though de facto standards are established by corporations from developed countries. The aim of this research is also to help improve administrative systems based on de jure standards, including the ISO and IEC, around the globe. Such reforms would improve national innovation systems both in developing and developed countries, through the improvement of the management system of standards.

\subsection{Theoretical contribution}

We identified the key determinants of the lifespan of standards and the relationship as Lifespan of standard $=\mathrm{f}$ (technological category (+/-)). This result leads to a different treatment of standards across technological categories. As the timely creation of a market is essential in the current innovation system, a correct timing for standards' review

\section{Scope of found scenario from this study}

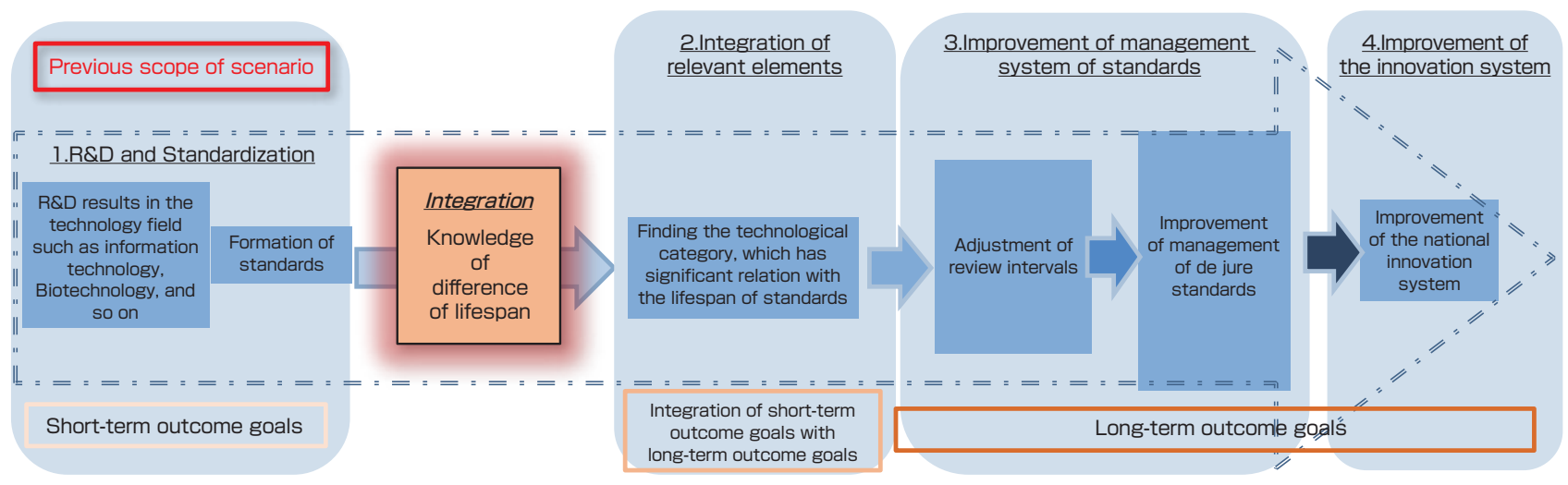

Fig. 2 Road map scenario for the improvement of the national innovation system through the management of standard 
is important and can lead to the implementation of more valuable standards. This is expressed as

$$
\max (\text { Value of standards })=\mathrm{f}\left(\mathrm{t}^{*}\right)
$$

where $t *$ is the equilibrium point of the review period in terms of the value of standards, in each technological category.

\subsection{Managerial contribution}

Our result shows that we can use the lifespan of standards as tools for the management of such standards, as in patent or copyright legal systems. We can reduce the administrative and related transaction costs for reviewing standards. We can adjust the current 5-year interval to longer intervals, for some categories, as our estimation results (Table 5) seem to suggest. Through this empirical analysis, a comprehensive management scenario for both the pre-standardization and post-standardization periods is presented for the first time as an explicit conceptual framework. This result applies to both the international standards' system in ISO and IEC and to each country's de jure standards' management system. Our result has potential global implications, since de jure standards are necessary tools in both developing and developed countries.

\section{Further study}

We study the general tendency of each technology sector. The next study will aim to investigate the lifespan and the reason behind each technology standard. For this, it is necessary to know the nature of the technology. The role of standards in terms of product life cycle should be discussed for each related product.

We proposed the scenario in Fig. 2. To improve the mindset for fostering innovation through the review term of the standardization, it is necessary to check the difference in the lifespan of each technology field when JISC plans the review schedule, which usually occurs on a yearly basis.

\section{Conclusion}

In our study, we presented a roadmap to innovation after the standards' formation is completed so as to integrate $R \& D$ results and standardization activities more effectively and comprehensively. For the purpose, this study focused on the lifespan of standards as the variable of interest. We normatively discussed the review interval of standards. First, we found an empirical relationship between the technology sectors and the lifespan of standards. This means that differences in technological characteristics have a strong influence on the lifespan of de jure standards. This is true for industrial sectors, such as (c6) "F: Shipbuilding" and (c2) "B: Mechanical engineering." We can optimize the review periods of standards following these results. In some contexts, extending the review interval can be appropriate. This may lead to a reduction in the cost of maintenance of standards and to adequate market creation. We also presented a road map scenario, focused on both the pre-standardization and poststandardization periods, to improve the national innovation system through the revision of the management system of standards, by referring to the research result of standardization in AIST. This result is beneficial to public agencies in Japan, as well as to international organizations, such as ISO, which deal with de jure standards with fixed review interval systems for several decades.

\section{Acknowledgements}

This study is conducted as part of the Project at Research Institute of Economy, Trade and Industry (RIETI). The author appreciates the valuable comments of the Discussion Paper seminar participants at RIETI, the support from Director Nagano, Director Yamamoto, Director Fukuda and Director Izumi of Technical Regulations, Standards and Conformity Assessment Unit at the Ministry of Economy, Trade and Industry (METI) and Professor Omori of the economics department at The University of Tokyo. This work was supported by JSPS KAKENHI Grant Number 15K03718.

\section{References}

[1] G. Tassey: Method for Assessing the Economic Impacts of Government $R \& D$, National Institute of Standards \& Technology, Gaithersburg (2003).

[2] H. Yasuda: Standardization activities on multimedia coding in ISO, Signal Processing: Image Communication, 1, 3-16 (1989).

[3] K. Zi and K. Blind: Researchers' Participation in Standardisation: a Case Study from a Public Research Institute in Germany, The Journal of Technology Transfer, 40 (2), 346-360 (2015). 
[4] A. Ono, M. Akamatsu and N. Kobayashi: Scenario in synthetic-type research: its role and description, Synthesiology-English edition, 9 (1), 27-41 (2016).

[5] OECD: Frascati Manual 2002: Proposed Standard Practice for Surveys on Research and Experimental Development, OECD, Paris (2002).

[6] W. B. Arthur: Competing Technologies, Increasing Returns, and Lock-In by Historical Events, Economic Journal, 99, 116-131 (1989).

[7] K. Blind: Explanatory Factors for Participation in Formal Standardization Processes: Empirical Evidence at the Firm Level, Economics of Innovation and New Technology, 15 (2), 157-170 (2006).

[8] K. Blind and A. Mangelsdorfa: Motives to Standardize: Empirical Evidence from Germany, Technovation, 48-49, 13-24 (2016).

[9] C. Antonelli: Localized Technological Change and the Evolution of Standards as Economic Institutions, Information Economics and Policy, 6 (3/4), 195-216 (1994).

[10] AIST: 2015 AIST REPORT, Tokyo (2016).

[11] S. Taniyasu, N. Hanari, Y. Horii and N. Yamashita: Standardization of environmental analysis methods of hazardous chemicals, Synthesiology-English edition, 5 (4), 270-286 (2013).

[12] T. Baba and M. Akoshima: A social system for production and utilization of thermophysical quantity data, Synthesiology-English edition, 7 (2), 49-64 (2014).

[13] T. Iijima, T. Abe and H. Itoga: Development of material testing equipment in high pressure gaseous hydrogen and international collaborative work of a testing method for a hydrogen society, Synthesiology-English edition, 8 (2), 61-69 (2015).

[14] Y. Hirata, N. Miyamoto, M. Shimizu, M. Yoshida, K. Hiramoto, Y. Ichikawa, S. Kaneko, T. Sasagawa, M. Hiraoka and H. Shirato: International standardization of four dimensional radiotherapy system, Synthesiology-English edition, 7 (4), 229-238 (2015).

[15] K. Kobara and S. Shin: Secure password authentication schemes and their applications, Synthesiology-English edition, 7 (3), 174-184 (2014).

[16] G. Hanaoka, S. Ohata, T. Matsuda, K. Nuida and N. Attrapadung: Methodology for designing cryptographic systems with advanced functionality based on a modular approach, Synthesiology-English edition, 7 (2), 92-104 (2014).

[17] T. Baba and M. Akoshima: A social system for production and utilization of thermophysical quantity data, Synthesiology-English edition, 7 (2), 49-64 (2014).

[18] Y. Tanaka, A. Momma, A. Negishi, K. Kato, K. Takano, K. Nozaki and T. Kato: Progress towards realizing distributed power generation with highly efficient SOFC systems, Synthesiology-English edition, 6 (1), 12-26 (2013).

[19] K. Sagawa and K. Kurakata: Estimation of legible font size for elderly people, Synthesiology-English edition, 6 (1), 38-49 (2013).

[20] A. Momma, K. Takano, Y. Tanaka and T. Kato: Evaluating uncertainty for the standardization of single cell/stack power generation performance tests for SOFC, SynthesiologyEnglish edition, 5 (4), 251-261 (2013).

[21] K. Iwao: International cooperation for the utilization of earth observational data in an integrated manner, SynthesiologyEnglish edition, 5 (3), 160-170 (2012).

[22] A. Tsuge and W. Kanematsu: An analysis method for oxygen impurity in magnesium and its alloys, Synthesiology-
English edition, 5 (1), 25-36 (2012).

[23] H. Ito: Integrated development of automotive navigation and route guidance system, Synthesiology-English edition, 4 (3), 162-171 (2012)

[24] W. Shin, M. Nishibori and I. Matsubara: Thermoelectric hydrogen gas sensor, Synthesiology - English edition, 4 (2), 99-107 (2011).

[25] H. Ujike: Developing an evaluation system of visually induced motion sickness for safe usage of moving images, Synthesiology-English edition, 5 (3), 139-149 (2012).

[26] Y. Takao and M. Sando: Products and evaluation device of cosmetics for UV protection, Synthesiology-English edition, 3 (2), 140-150 (2010).

[27] A. Satoh, T. Katashita and H. Sakane: Secure implementation of cryptographic modules, SynthesiologyEnglish edition, 3 (1), 86-95 (2010).

[28] S. Osawa, T. Takatsuji and O. Sato: High accuracy three-dimensional shape measurements for supporting manufacturing industries, Synthesiology-English edition, 2 (2), 95-106 (2009).

[29] K. Wakita, T. Igawa, S. Takarada and Y. Fusejima: Creation of seamless geological map of Japan at the scale of 1:200,000 and its distribution through the web, Synthesiology - English edition, 1 (2), 73-84 (2008).

[30] K. Kurakata and K. Sagawa: Development and standardization of accessible design technologies that address the needs of senior citizens, Synthesiology - English edition, 1 (1), 15-23 (2008).

[31] A. E. Leiponen: Competing Through Cooperation: The Organization of Standard Setting in Wireless Telecommunications, Management Science, 54 (11), 1904 1919 (2008).

[32] S. Tamura: Generic Definition of Standardization and the Correlation between Innovation and Standardization in Corporate Intellectual Property Activities, Science \& Public Policy, 40 (2), 143-156 (2013).

[33] JISC: Japan's Standardization Policy 2013, Japanese Industrial Standards Committee, Tokyo (2013).

[34] S. Tamura: Who participates in de jure standard setting in Japan? The analysis of participation costs and benefits, Innovation: Management, Policy \& Practice, 17 (3), 400415 (2015).

[35] P. A. David: Clio and the economics of QWERTY, The American Economics Review, 75, 332-337 (1985).

[36] H. Yamada and S. Kurokawa: How to profit from the de facto standard-based competition: learning from Japanese firms' experiences, International Journal of Technology Management, 30 (3/4), 299-326 (2005).

[37] K. Blind and A. Jungmittag: Trade and the impact of innovations and standards: the case of Germany and the UK, Applied Economics, 37, 1385-1398 (2005).

[38] Japanese Standards Association: JIS handbook, Tokyo (2011) (in Japanese).

[39] T. M. Egyedi and M. H. Sherif: Standards Dynamics through an Innovation Lens: Next-Generation Ethernet Networks, IEEE Communications Magazine, 48 (10), 166-171 (2010).

[40] M. H. Sherif: A Framework for Standardization in Telecommunications and Information Technology, IEEE Communications Magazine, 39 (4), 94-100 (2001).

[41] K. Jakobs, R. Procter and R. Williams: Standardisation, Innovation and Implementation of Information Technology, Computers and Networks in the Age of Globalization, 57, 201-217 (2001). 


\section{Author}

\section{Suguru TAMura}

Joined the Ministry of International Trade and Industry, and worked at the Technology Evaluation and Research Division, Industrial Science and Technology Policy and Environment Bureau, and at the Council for Science and Technology Policy, Cabinet Office. Associate Professor of the Faculty of Science and Engineering, Waseda

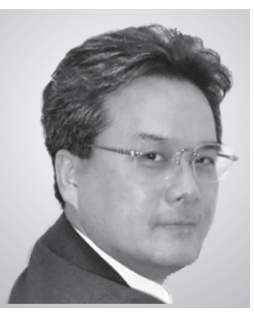
University from 2009 to 2012. Senior Fellow of the Research Institute of Economy, Trade and Industry from 2012. Main accomplishments include publication in the Synthesiology, Journal of the American Ceramic Society, Science and Public Policy, International Journal of Technology Management, Technovation and others. Research topics include the innovation management and the R\&D evaluation method.

\section{Discussions with Reviewers}

\section{Overall}

\section{Comment (Naoto Kobayashi, Waseda University)}

This paper presents original results, which are useful and interesting from the viewpoint of optimizing the review period of the standards that contribute to innovation. The process is expected to help the efficient management of standards. Therefore, this paper deserves to be published in Synthesiology owing to the improvement of the synthetic method of logical expression.

\section{Comment (Hiroaki Tao, AIST)}

By analyzing about 4500 JIS standards, this paper describes the influence of factors, such as technology categories, ISO standards, legislative application, review records, and the type of standards (design, measurement, and product), on the lifespan of standards. The paper is a valuable contribution to be published in Synthesiology as there have been no papers that address the lifespan of de jure standards and the policy implications for innovation systems based on the improvement of technology standards' management.

\section{Relevance of lifespan to the standards' properties Comment (Naoto kobayashi)}

The lifespan of standards was investigated by introducing the technology category as an independent variable in the regression analysis. It is necessary to analyze the relevance of the lifespans to the properties of the lifespan distribution shown in Fig. 1. For example, in C: Electronic and electrical engineering, the frequency of the lifespan decreases almost monotonically toward the longer lifespan. In T: Medical equipment and safety appliances, it is found that many specific standards have a lifespan of about 50 years. I recommend that you describe the relevance of the results of your current analysis to the properties of standards in the corresponding technology category.

\section{Answer (Suguru Tamura)}

The aim of this study is to present a statistical analysis for the existent categories. It is possible, however, to study the characteristics of technology standards and their statistical properties in a narrower technology classification. Examining the reason why individual standards differ in age is a subject for future research. This point is added in Chapter 7, "Further research."

\section{Revising the review interval of standards Comment (Hiroaki Tao)}

This study's proposition that innovation systems can be improved through the management of standards in addition to the formation of technology standards is novel and important. However, the resulting policy implications are limited to extending the review interval and, as a consequence, seem to focus only on the reduction of management costs. The recommendation is an obvious one. Could you present a recommendation on reducing the review interval that would improve innovation speed?

\section{Answer (Suguru Tamura)}

According to the results presented in Table 5, the coefficient is large enough to serve as evidence in support of our discussion on the policy implications. Several coefficients are positive and almost exceed the value two. This value corresponds to the situation where the review interval tends to be $50 \%$ longer than the current five-year interval. Nevertheless, there are not enough large and negative coefficients. Hence, in the discussion on policy implications, we consider only the extension of the review interval.

\section{Technology classification and review intervals Comment (Hiroaki Tao)}

In Fig. 1, B (Mechanical engineering) and $K$ (Chemical engineering) seem to have two peaks. This suggests that setting a single and fixed review interval, which depends on the existing technology categories, is not rational. Could you comment on this?

\section{Answer (Suguru Tamura)}

Under the current system, reviews with a specific interval are a requirement. Hence, to formulate policy recommendations, it is necessary to consider a review interval. In our analysis, the review periods correspond to the pre-existent JIS technology categories, and the revision of the review period is suggested according to those categories. This suggestion depends on the existing framework for technology classification. In addition, we study the factors that affect the age of technology standards in each technology category as a whole. Let us consider the example of smoking and the health risk it poses from the medical point of view. There are smokers, who do not suffer from lung cancer, but, on average, the ratio of cancer sufferers is higher among smokers when we consider the difference between groups of smokers and non-smokers. When we contemplate this result in the context of policy implications and the policy framework, we consider the average figure for each group, rather than data on a single individual. This example illustrates that, for statistical analysis, the established group category is used in many cases. For classification purposes in our study, we follow the category of JIS technology standards, which has been used in the literature for a long time.

One may point out that, for example, to divide each existing technology category into subgroups and to decide the review interval according to the subgroup is theoretically possible. However, to achieve that, exploring other category classification criteria is essential. This essentially means searching for the reason for the different lifespan of each standard. We think that this is not within the research scope of this paper and the issue is discussed as a subject for further research in Chapter 7, "Further research."

\section{Analysis concerning the characteristics of technology categories \\ Comment (Hiroaki Tao) \\ It is contemplated that the influence of ISO standards,}


legislative application, review records, and the type of standards on the lifespan is different in each technology category, but the differences in such an influence between technology categories does not seem to be analyzed in the present study. Is it difficult to address this in your study?

Moreover, emerging, mature, or obsolete technologies change over time differently in each technology category. It has been suggested that this influence manifests in the number of standards produced, the frequency of reviews, and the number of aborted standards. Is it possible to observe the technology transitions in each technology category?

\section{Answer (Suguru Tamura)}

In this study, we first control the influence of factors such as ISO standards, legislative application, review records, and the type of standards. Later, we discuss the influence of technology categories. When we observe the variance in age, we should recognize that the source of the variance is ISO or technology categories. Otherwise, our conclusions concerning the factors' influence and policy implications are erroneous. Therefore, we use the control variables to isolate the influence of the unintended factors. With this method, the factor of interest - the technology category - is analyzed separately. Certainly, if we were addressing a different research goal, we could observe the influence of ISO by treating the other factors as control variables, rather than as policy variables. The current research setting largely corresponds to our research goal. For a discussion on this theoretical issue, see, for instance, Introductory Econometrics: A Modern Approach by Wooldridge.

Finally, the control variables we used in this study are:

1. ESY, in order to capture the generation differences when standards were established;

2. ENY, in order to capture the generation differences when standards were abolished.

Through this treatment, we can estimate the influence of categories on age by excluding the influence of the generation background. On the other hand, we can estimate the influence of the generation difference by treating ESY and ENY as policy variables and including the technology categories as controls, although such setting diverges from our research goal. This analysis shows that, for example, the standards established in certain decades tend to have a longer-or shorter-lifespan than those established in other decades. 